\title{
Physical Attractiveness and Romantic Relationships: A Review
}

Lamy L*

Professor of Social Psychology, Paris University, France
ISSN: 2639-0612

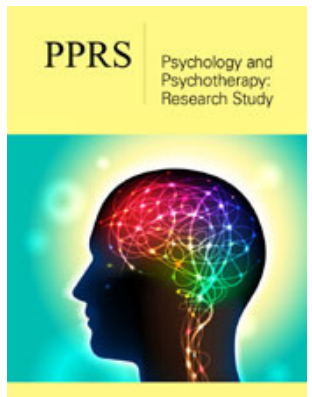

*Corresponding author: Lamy L, Professor of Social Psychology, Paris University, France

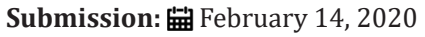

Published: 鮆February 19, 2020

Volume 3 - Issue 4

How to cite this article: Lamy L. Physical Attractiveness and Romantic Relationships: A Review. Psychol Psychother Res Stud. 3(4).PPRS.000566.2020.

DOI: 10.31031/PPRS.2020.03.000566

Copyright@ Lamy L, This article is distributed under the terms of the Creative Commons Attribution 4.0 International License, which permits unrestricted use and redistribution provided that the original author and source are credited.

\begin{abstract}
The aim of this article is to present an argument on the physical attractiveness-love linkage. It contributes to the discussion as to whether beauty is enough to inspire love, or it is only associated with preferences for an ideal partner. Next, we summarize the studies demonstrating the effects of beauty illusions on romantic relationships. Finally, we present the evolutionary and socio-cultural interpretations on the meaning of physical attractiveness.
\end{abstract}

\section{Physical Attractiveness Elicits Attraction Rather than Love}

When asked to state their ideal romantic-partner preferences, men tend to overestimate women's physical attractiveness, whereas women tend to overestimate men's earning prospects [1,2]. Beyond this gender-related difference, however, both men and women prefer attractive, as compared to non-attractive partners. Attractive individuals are more popular, at least among members of the opposite gender, and they are more successful in dating relationships [3]. In line with these findings, it could be expected that feelings of love and affection would be more readily directed towards attractive individuals. But it is striking that this hypothesis was not supported by empirical studies. Among dating partners, neither independent observer, self, nor partner ratings of attractiveness are linked with the level of love an individual receives from his/her partner [4]. For men and women alike, beauty has no advantage in terms of love received, or given. Attractive women are more desired as romantic partners. Attractive men have more cross-gender interactions. Thus, it could be stated that physical attractiveness creates attraction, but it is not enough to create love.

\section{Physical Attractiveness and Illusions}

Among dating or married partners, positive illusions have been found to enhance feelings of trust, commitment, security, satisfaction and love [3]. The phenomenon [5,6] have termed the 'love-is-blind bias' is a positive illusion of partner physical attractiveness, such that men and women rate their current partners as more attractive than themselves and their former partners. The love-is-blind bias is positively correlated with self-esteem, relationship satisfaction, and romantic love. Moreover, [3] showed that men and women rate their partners as more attractive than their partners rate themselves. They also found relationship quality to be higher when individuals hold a positive illusion about their partners' physical attractiveness, especially in older couples. In addition, individuals who rate their partners as more attractive than themselves love their partners more than individuals who rate themselves as more attractive than their partners [4]. A different kind of bias is related to our ability to leave aside our ideal romantic-partner preferences, when confronted to real potential romantic partners. Despite the fact that men consistently express a preference for physically attractive women, in a real-life setting [7] they display more relational investment to women similar to them regarding physical attractiveness, as compared to women dissimilar to them (i.e., more attractive or less attractive). Stated ideal preferences are uncorrelated with in vivo preferences during a speed-dating event [2]. Thus, it may be possible that individuals are partially unaware of the reasons why they engage in a relationship. Women and men alike value physical attractiveness, but this preference has little or no effect when they actually interact with a potential partner. 


\section{The Hidden Meaning of Physical Attractiveness}

From an evolutionary point of view, physical attractiveness is related to health, fertility, and genetic quality $[8,9]$. Some physical features, such as symmetry or female waist-to-hip ratio (WHR), communicate information about health and fertility, and humans have evolved to interpret them as physical beauty. More specifically, female WHR has been found consistently to be related to health, e.g., cardiovascular disorders, adult-onset diabetes, certain forms of cancer, hypertension, or premature mortality [9]. It is also a reliable indicator of reproductive capability. In addition, both men and women rate female bodies with low WHR as more attractive. Therefore, it seems that men who fall in love with beautiful women, not only increase their hedonic satisfaction from contemplating beauty, or improve their social image, which is strongly associated with their partner's beauty. They also improve their chances of having healthy children.

Beauty has also been thought of as an oppressive socio-cultural imperative. And indeed, judgements of physical beauty are part of an overall impression of social worth. Numerous personal qualities are attributed to the most beautiful individuals and make them more likeable. For instance, we assume they are warmer and happier, more assertive, emotionally more stable. We assume they have more friends, a happier marriage and a more prestigious occupation than unattractive individuals. Partners' attractiveness is strongly connected with their social desirability. Nevertheless, beyond first encounters, attractive individuals might gain little from the 'beautiful-is-good' effect. Daily interactions provide countless opportunities to check whether a partner's actual qualities live up to expectations. And when this is not the case, the initial sympathy could quickly turn into bitterness and resentment.
The gaze of love seeks beauty even where it is hard to find it [10]. But even with the gaze of love, beauty raises expectations and hope which sooner or later would need to be confirmed.

\section{References}

1. Buss DM (1989) Sex differences in human mate preferences: Evolutionary hypotheses tested in 37 cultures. Behavioral and Brain Sciences 12(1): 1-14.

2. Eastwick P W, Finkel E J (2008) Sex differences in mate preferences revisited: Do people know what they initially desire in a romantic partner? J Pers Soc Psychol 94(2): 245-264.

3. Barelds D, Dijkstra P (2009) Positive illusions about a partner's physical attractiveness and relationship quality. Personal Relationships 16(2): 263-283.

4. Critelli JW, Waid LR (1980) Physical attractiveness, romantic love, and equity restoration in dating relationships. J Pers Assess 44(6): 624-629.

5. Swami V, Stieger S, Haubner T, Voracek M, Furnham A (2009) Evaluating the physical attractiveness of oneself and one's romantic partner. Journal of Individual Differences 30(1): 35-43.

6. Swami V, Allum L (2012) Perceptions of the physical attractiveness of the self, current romantic partners and former partners. Scand J Psychol 53(1): 89-95.

7. Straaten VI, Engels R, Finkenauer C, Holland RW (2009) Meeting your match: How attractiveness similarity affects approach behavior in mixed-sex dyads. Pers Soc Psychol Bull 35(6): 685-697.

8. Ehlenbracht D, Stavrova O, Fetchenhauer D, Farrelli D (2018) The synergistic effect of prosociality and physical attractiveness on mate desirability. Br J Psychol 109(3): 517-537.

9. Singh D, Singh D (2011) Shape and significance of feminine beauty: An evolutionary perspective. Sex Roles 64: 723-731.

10. Sadr J, Krowicki L (2019) Face perception loves a challenge: Less information sparks more attraction. Vision Res 157: 61-83. 